\title{
$\angle S$ Research S Suare \\ Kinetics of the Cationic bio-reduction involved in the biosynthesis of silver nanoparticles from Leea Coccinea Leaves
}

\author{
María del Carmen Travieso Novelles ( $\sim$ mcarmen@censa.edu.cu ) \\ Laboratory of Chemical-Ecology, National Center for Animal and Plant Health (CENSA), San José de las \\ Lajas, Mayabeque, Cuba https://orcid.org/0000-0002-5672-349X
}

\section{Lianet Díaz Pérez}

Laboratory of Chemical-Ecology, National Center for Animal and Plant Health (CENSA), San José de las Lajas, Mayabeque, Cuba

\section{Annie Rubio Ortega}

Laboratory of Chemical-Ecology, National Center for Animal and Plant Health (CENSA), San José de las Lajas, Mayabeque, Cuba

\section{Beatriz Alvarez Pita}

Laboratory of Chemical-Ecology, National Center for Animal and Plant Health (CENSA), San José de las Lajas, Mayabeque, Cuba

\section{Verónica Navarro Hernández}

Laboratory of Chemical-Physical Quality Control, National Center for Animal and Plant Health (CENSA), San José de las Lajas, Mayabeque, Cuba

\section{Adrian González Travieso}

Pharmaceutical Research Group, National Center for Animal and Plant Health (CENSA), San José de las Lajas, Mayabeque, Cuba

\section{Oriela Pino Pérez}

Laboratory of Chemical-Ecology, National Center for Animal and Plant Health (CENSA), San José de las Lajas, Mayabeque, Cuba

\section{Research}

Keywords: silver nanoparticles, kinetic, flavonoids, Leea coccinea, nanotechnology, green synthesis.

Posted Date: June 1st, 2021

DOl: https://doi.org/10.21203/rs.3.rs-551536/v1

License: (c) (i) This work is licensed under a Creative Commons Attribution 4.0 International License. Read Full License 


\section{Abstract}

The resistance of microorganisms to conventional antimicrobials is one of the most serious health problems that affect not only the human, but also animals and plants, making the search for antimicrobial active ingredients a priority of global research. Green synthesis of antimicrobial silver nanoparticles (AgNPs) is a simple, cost-effective, rapid, reproducible, and environment friendly alternative for which numerous plant species have been reported for this purpose. Previous studies have shown the potential of Leea coccinea leaves in to the biosynthesis of antimicrobial silver nanoparticles. The current research aimed to study the kinetics of the reaction of synthesis of AgNPs by cationic bio-reduction from this botanical bioresource. A technology for the synthesis of AgNPs was established and the influence of operational parameters such as the bio-reduction conditions and the kinetics of the reaction were studied. AgNPs were characterized at different times by UV-VIS spectroscopic method, scanning electron microscopy, determination of particle size, and Z potential through Dynamic Light Scattering technique (DLS). Addition of tensoactive substances was evaluated for the stabilization of the suspension of nanoparticles. The results showed that spherical AgNPs smaller than $100 \mathrm{~nm}$ were obtained, which were visually identified by the formation of a dark brown complex with maximum absorption at $470 \mathrm{~nm}$. Kinetic studies demonstrated the influence of the initial plant material on speed and performance, making evident a complex phenomenology with the possible occurrence of parallel reactions, which points to the possible reaction of different reducing compounds contained in this natural source. Addition of surface agents, such as SDS $(0,5 \%)$ or maltose $(0,5 \%)$, improved the stabilization in the aqueous medium, suggesting the continuation of studies to develop pharmaceuticals formulations based on AgNPs.

\section{Introduction}

Antimicrobial Resistance (AMR) has been identified by the World Health Organization (WHO) as one of the greatest threats to global health (Quiñones 2017; WHO 2016). AMR is a complex, genetic and environmental phenomenon that occurs when microorganisms (bacteria, fungi, viruses and parasites) undergo changes when exposed to conventional antimicrobials (antibacterials, antifungals, antivirals, antimalarials or anthelmintics) and modify their behavior and sensitivity (WHO 2017; UN 2017). It is a global problem that not only affects humans, but also animals and plants (WHO 2017; OIE 2013; FAO 2016; Serra 2017). The search for new antimicrobial active ingredients is a global research priority. With the emergence of nanotechnologies, the scientific community has accessed tools that are revolutionizing approaches to the discovery of new active principles, due to modifications in a property as important as particle size with the use of these technologies, sizes in the order of the nanoscale are achieved, with the consequent impact on the bioavailability of these molecules at the site of action (Travieso et al. 2017). All this has allowed nanotechnology to attract great interest today and to be projected as a promising solution to problems in the scientific and technological field. However, many of the technologies applied to obtain nanoparticles (NPs), fundamentally based on physical and chemical processes, show disadvantages not only from the economic (high costs) or technological (need for specialized equipment) points of view, but also from the environmental aspects because of the required use of highly toxic organic solvents and other aggressive chemical compounds, reasons among others, that make current efforts focus on more feasible and environmentally friendly technologies. Such is the case of the biological methods (Singh et al. 2019) that use natural sources 
(microorganisms, plants, algae, or derived substances). Although dissimilar methods have been used to obtain NPs from plants (Travieso et al. 2017), the bio-reduction of metal cations is the most used and promising method for the formation of biogenic nanoparticles with antimicrobial activity (Mohammadlou et al. 2016; Roy 2017), being the metal salts of the (groups 10, 11 and 12) the most used as sources of the metallic cations of silver $\left(\mathrm{Ag}^{+}\right)$, gold $\left(\mathrm{Au}^{3+}\right)$, copper $\left(\mathrm{Cu}^{2+}\right)$ and zinc $\left(\mathrm{Zn}^{2+}\right)$ (Sarkar and Paul 2017; Rao et al. 2016; Kasithevar et al. 2017). Numerous are the studies showing the antimicrobial properties of AgNPs against a wide variety of pathogens such as bacteria (Travieso et al. 2018; Rautela et al. 2019), fungi (Huang et al. 2020) and viruses (Haggag et al. 2019). In recent years, several authors reported the use of a great diversity of botanical sources for the green synthesis of AgNPs (Travieso et al. 2017; Gupta and Chauhan 2017). Plant parts such as leaves (Meena et al. 2020), seeds (Rautela et al. 2019), flowers (Kumar et al. 2020), bulbs (Mosaviniya et al. 2019), root (Behravan et al 2018), among others, are studied as reducing compounds sources in the biosynthesis of AgNPs. However, sustainability is a critical point to take into account in the design of a technology based on natural sources, with a view to guaranteeing the required production levels. Leea coccinea which belongs to a genus known for its great richness in phytochemical compounds such as flavonoids (Singh et al. 2019), and it was recently identified as a promising source of reducing compounds (Travieso et al. 2021). The objective of this work was to study the kinetics of cationic bio-reduction by the reducing compounds in the aqueous extract of Leea coccinea leaves, as well as to evaluate surfactants for the stabilization of the biosynthesized silver nanoparticles in the aqueous medium.

\section{Materials And Methods}

\section{Materials}

Silver nitrate (Merck), sodium dodecyl sulphate (SDS) (Merck), Polysorbate 80 (Tween 80) (Lobachemie), and Maltose (Merck) reagents were pure for analysis. All the solutions were prepared with deionized water. The fresh Leea coccinea leaves were collected in San José de las Lajas, province of Mayabeque, Cuba (Travieso et al. 2021). The collected leaves were washed with deionized water, cut into small pieces, and macerated with distilled water $(1: 8)(\mathrm{W} / \mathrm{V})$ at $90^{\circ} \mathrm{C}$ for 10 minutes. Then they were cooled and filtered through Whatman No. 1 paper.

\section{Biosynthesis of AgNPs. Bio-reduction conditions}

The synthesis of the AgNPs was carried out by means of the static bio-reduction reaction of metallic cations by the reducing compounds in the aqueous extract of the plant under study. An aliquot of this aqueous extract was taken and made react with the $\mathrm{AgNO}_{3}$ solution $(2 \mathrm{mM})$ in the ratio $(1: 9)(\mathrm{V} / \mathrm{V})$. The reaction mixture was homogenized with a mechanical stirrer (IKA-VF2) and allowed to stand for 24 hours. The occurrence of the reaction of Ag cations was monitored at 5 minutes, and 1 and 24 hours. The appearance of a dark brown complex was indicative of the formation of AgNPs. The colloidal ssuspensions were stored at room temperature $\left(27 \pm 2^{\circ} \mathrm{C}\right)$ in the dark until physicochemical and morphological characterization studies.

The stages of the technology for the synthesis of AgNPs were established and the Critical Points (PC) related to the quality and performances of the nanostructures were identified. Operational parameters were studied which included the initial quality of the plant raw material, and specifically the use of fresh (F) or dry (D) plant 
material; the bio-reduction conditions (kinetics). Also, surfactant-stabilizing agents for AgNPs in the aqueous medium were evaluated to the future design of active nuclei for different types of formulations.

The study of the kinetics of the reaction was carried out by monitoring the reduction of Ag cations and presence of the colored complex indicative of the formation of AgNPs at different times $\left(t_{0}, 5,30,60,120\right.$, 180, 240, 360, 720, 1080, 1320, 1440, 2160 and 4320 minutes) by UV-Vis spectrophotometry. At each time, an aliquot of the AgNPs suspension was taken and diluted with distilled water (1:8) (V/V) to characterize of the colloidal suspension by UV-Vis spectrophotometry (Vis-723 G spectrophotometer, Rayleigh) in a I range between $380 \mathrm{~nm}$ and $800 \mathrm{~nm}$. The variation of the $\mathrm{H}^{+}$ion concentration (product of the bio-reduction reaction) over time was determined in the entire reaction pool by means of a pH meter (Mettler Toledo Instrument). Curves of Maximum absorbance ( $\mathrm{A}$ ) vs time (minutes), as well as $\mathrm{pH}$ variation versus time (minutes) were designed. The type of reaction was determined by the differential method.

The reaction was stopped at different points $(6,12,18$ and 24 hours) by centrifuging at $10000 \mathrm{rpm}$ for 15 minutes (Eppendorf ${ }^{\mathrm{T}} \mathrm{M}$ Centrifuge 5424R) and removing excess cation donor solution. The precipitated AgNPs (pellets) were stored at room temperature $\left(25 \pm 2{ }^{\circ} \mathrm{C}\right)$ in the dark for the physicochemical and morphological characterization studies as a function of time.

\section{Influence of the initial plant material}

Taking into account the importance of the quality of the plant raw material, the influence of drying on the quality and performance of the synthesized nanostructures was studied. Synthesis from fresh and dry plant material was comparatively evaluated. The leaves were dried at room temperature $\left(27-30^{\circ} \mathrm{C}\right)$ in the shade. The dried plant material was kept in nylon bags for 9 months. The yield of the synthesis of AgNPs was determined, both from fresh and dry plant material, by measuring of the dry weight of $1 \mathrm{~mL}$ of the suspension for triplicate on an infrared balance (Sartorious MA35) and calculated with relation to the initial mass of the plant material.

\section{Influence of surfactant-stabilizing agents}

Surface agents, such as tween 80 at 0,5\% (TW 0,5\%), maltose at 0,5\% (Mt 0,5\%) and SDS at 0,5\% (SDS 0,5 $\%)$, were evaluated. Their influence on the particle size and the $Z$ potential were determined as a measure of the stabilization of the nanostructures in the aqueous medium through Dynamic Light Scattering technique (DLS) with Nano ZS90 instrument (Malvern, UK).

\section{Characterization of the AgNPs}

\section{Determination of particle size and Z potential}

The purified NPs contained in each vial were reconstituted in $2 \mathrm{~mL}$ of distilled water (Lichrosolv water for chromatography, Merck) using the mechanical shaker (IKA-VF2), and subsequently sonicated in an ultrasonic bath (WiseClean) for 10 minutes. An aliquot of $1 \mathrm{~mL}$ was taken and placed in polyethylene cuvettes for DLS particle size determinations using a particle size analyzer (Nano ZS90 instrument, Malvern, UK). 
Likewise, the effects of the surfactants were evaluated at 12 hours. A selection of four samples (12h WT, 12h

TW 80, 12h Mt, y 12h SDS) was made from those previously analyzed to determine the zeta potential by using the same Particle Size Analyzer (Malvernzetasizer). Each vial was shaken at high speed with the mechanical shaker and subsequently sonicated for 10 minutes. An aliquot of $2 \mathrm{~mL}$ was taken for each measurement.

The structural properties of the nanostructures formed at 6, 12, 18 and 24 hours were determined by SEM (MIRA 3 LMU TESCAN). The suspended sample was placed as a thin layer on carbon adhesive tape and once dry it was coated with gold- vanadium $(5 \mathrm{~nm})$ using the Desk Sputter Coater DSR1. The quantitative analysis was carried out using EDX (Oxford Instrument) to determine the main elements present and confirm the formation of NPs.

\section{Statistical analysis}

All determinations were carried out in triplicate and the results were expressed as the average value in the range of the standard deviation. For comparative studies, data were statistically processed using a simple analysis of variance and the means were compared using the Duncan's multiple range test or $\mathrm{T}$ test, with a significance level of 5\%, using InfoStat/L Versión 2016 (Di Rienzo et al. 2016).

\section{Results And Discussion}

\section{Biosynthesis of AgNPs. Conditions of bio- reduction}

\section{Influence of the initial plant material}

In the synthesis technologies of AgNPs based on biological processes, where the source of reducing compounds is of botanical origin, plants or parts of plants (e.g. leaves, flowers, seeds, bulbs, fruits) constitute the fundamental raw material. Therefore, in addition to the abundance of the compounds responsible for the reaction it is essential to know all the factors that influence the concentration and quality of these compounds. Drying processes are unitary operations that are part of the processing of plant material in order to guarantee the reproducibility of an industrially scalable process and the protection of this biological material from microbial contamination (bacteria and fungi). Although it is known that the composition of secondary metabolites in plants varies with the edaphoclimatic conditions (Pino et al. 2013), the influence of drying on the synthesis of AgNPs was evaluated in the present study.

The influence of the drying of the plant material on the synthesis of AgNPs was demonstrated, not only by the color change observed with respect to the organoleptic properties of the extracts obtained (Figure $1 \mathrm{C}$ and $\mathrm{G}$ ), but also by the differences in speed and yields of the bio-reduction reaction. In this sense, the reaction with the extract of fresh leaves started instantly (before 5 minutes), and the color drastically changed to dark brown (Figure $1 \mathrm{D}$ ), while the reaction with the dry leaves was after one hour (Figure 1H). Regarding the yields of the crude suspension, they were statistically superior in the synthesis with the fresh plant material $p \otimes 0.05$ (Figure 2).

\section{Kinetics of the bio-reduction}


The results of the kinetic study of the synthesis reaction of AgNPs at different times $\left(t_{0}, 5,30,60,120,180\right.$, $240,360,720,1080,1320,1440,2160$, and 4320 minutes) showed different behavior depending on the starting plant material (fresh and dry) (Figure 3).

Monitoring of the UV-Vis spectra confirmed that the reaction with the fresh material started instantaneously (Figure 3 and 4 A), given by the occurrence of a sudden color change from light green to dark brown, and by the presence of a well-defined peak at $\lambda_{\max } 440 \mathrm{~nm}$. Likewise, the increase in absorbance over time was evident until 1320 minutes (end of the reaction), which indicated a concentration increase of AgNPs over time what points to compliance with the Beer-Lambert law. From this time on the absorbance remained constant.

However, monitoring of the UV-Vis spectra with the dry material showed the beginning of the reaction after 180 minutes (Figures 3 and 4 B), made evident by the presence of the characteristic peak with $\lambda_{\max }$ of 440 $\mathrm{nm}$. In this case, the increase in absorbance over time was lower with respect to fresh plant material, until 1320 minutes (end of the reaction in both cases), suggesting the degradation of the reducing compounds and the loss of their properties. These results point to the need to carry out stability studies of the plant raw material in order to establish the useful life time and the optimal storage conditions.

The results were confirmed by monitoring the variation of $\mathrm{pH}$ over time (Figure 5) and observing the decrease of this indicator from the beginning of the reaction in the case of fresh plant material. As the AgNPs are formed, the $\mathrm{pH}$ decreases due to the release of $\mathrm{H}^{+}$by the formation of nitric acid, which slightly acidifies the medium. In the case of the dry material, no changes in $\mathrm{pH}$ were practically observed until 180 minutes, which corroborated that the reaction started at this time.

Numerous studies have shown the influence of $\mathrm{pH}$ on the morphology and stability of AgNPs. It is suggested that with increases in $\mathrm{pH}$ to basic values the concentration of AgNPs increases. Likewise, it was shown that the production of larger NPs occurs at acid $\mathrm{pH}$, while the formation of smaller and slightly stable NPs is favored by basic pH (Singh et al. 2020; Oluwasogo et al. 2019; Nasar et al. 2019; Handayani et al. 2020), so that the basic $\mathrm{pH}$ is ideal for the formation of AgNPs (Nasar et al. 2019). Other authors showed the influence of $\mathrm{pH}$ on nanostructure shapes, and they reported shapes between spherical and rods at basic $\mathrm{pH}(\mathrm{pH}=11.1)$, while triangular plate nanostructures or polygonal particles were obtained at acidic $\mathrm{pH}(\mathrm{pH}=5)(\mathrm{Handayani}$ et al. 2020).

The results of the study of the kinetics of the bio-reduction reaction when the differential method was applied revealed a complex phenomenology where different kinetic mechanisms were expected to occur due to the presence of dissimilar families of secondary metabolites. These metabolites could have reducing properties and the possible occurrence of concurrent or non-concurrent parallel reactions, self-catalysis, etc., were likely to occur (Figure $6 \mathrm{~A}$ and B). Further studies should clarify the possible reactions and end products.

The results obtained point to the technical feasibility of using fresh plant material for the synthesis of AgNPs with $L$. coccinea because of the higher yields and a faster bioreduction reaction. For this reason, subsequent studies were performed on AgNPs biosynthesized with fresh leaves.

\section{Characterization of the AgNPs}


The morphology of the AgNPs synthesized at different times was examined by SEM, and abundant NPs were observed to have spherical shapes and diameters less than $100 \mathrm{~nm}$ at all times $(6,12$, and 24 hours) of the synthesis (Figure 7A-D). The magnification of the images showed average diameters of 70-90 nm. Many authors agree on the strong agglomeration due to the electrostatic interactions between metal ions (Chen et al. 2016).

\section{Determination of particle size}

The particle size determinations by the DLS method for AgNPs synthesized with fresh plant material showed diameters less than $100 \mathrm{~nm}$ (Figure 8), and the high agglomeration that the nanostructures showed in the aqueous medium (-21.30 $\mathrm{mV}$ ) (Figure $8 \mathrm{~B})$ ), which corroborated the results obtained by SEM.

\section{Analysis by EDX}

The results of the qualitative analysis using EDX (Oxford Instrument) at different times (6, 12 and 24 hours) showed a high percentage of Ag from the first six hours of the reaction $(n=3)$, made evident by the strong signals in the range of $2-4 \mathrm{keV}$ and the presence of carbon and oxygen indicative of hybrid NPs, with an organic component (e.g., flavonoid) covalently bound to the metallic element (Figure 9). Likewise, the high compaction demonstrated its crystalline nature (Singh et al. 2019; Kasithevar et al. 2017; Oluwasogo et al 2019; Moodley et al. 2018) due to the reduction of Ag cations by the reducing compounds contained in the aqueous extract of $L$. coccinea leaves.

\section{Influence of surfactant-stabilizing agents}

MNPs are characterized by the easy conversion of monomeric and dimeric forms, to more stable aggregate forms in aqueous medium. However, numerous studies have shown that this natural tendency of AgNPs to form aggregates and agglomerates affects the biological activity (Bélteky et al. 2019). In this sense, the use of surfactants and stabilizers are studied with the aim of achieving the greatest stability of the nanostructures in the environment. The results of evaluating different surface active agents in the stabilization of the suspension of AgNPs, by determining the particle size (Figure 10) showed that all the evaluated surface active agents kept this indicator less than $100 \mathrm{~nm}$, except Mt with which an increasing trend from 89.62 to $122.4 \mathrm{~nm}$ was observed. Similarly, although there were no significant differences, an decreasing trend from 102.10 to $81.61 \mathrm{~nm}$ was observed over time with SDS.

On the other hand, the results by determining the Z potential (Malvern zetasizer) (Figure 11) showed that, excepting Tw 80, all the substances improved the stabilization of the nanostructures with respect to the aqueous medium, being SDS the best. A colloidal suspension is considered stable when the $Z$ potential is outside the range $\pm 30 \mathrm{mV}$ because the surface charge prevents the particles from aggregating (Duval et al.2019; Salvioni et. 2017). These results agree with those obtained by other studies on AgNPs synthesis with plants reporting similar Z potentials (Roy and Anantharaman 2017; Mohanta et al. 2017).

The $Z$ potential provides the electrokinetic potential in colloidal systems because its value can be related to the stability of colloidal dispersions and indicates the degree of repulsion between adjacent charged particles in a dispersion (Salvioni et. 2014). Because of the agglomeration tendency of AgNPs, due to the 
electromagnetic forces between them, destabilization and sedimentation are frequent, depending on the size of the aggregates, and affect the biological activity (Bélteky et al. 2019). For this reason, numerous studies are carried out to design stabilized systems based on AgNPs; however, their results not always are in agreement (Bae et al. 2011; Chen et al. 2016).

\section{Conclusion}

The present research reports the kinetic of the bio-reduction to biosynthesize fluorescent silver nanoparticles from aqueous extract of $L$. coccinea fresh and dry leaves. Drying process of the plant material showed to be a critical point that determined the kinetics of bio-reduction, which were complex and involved possible parallel reactions. The biosynthesized AgNPs had a spherical shape and a size less than $100 \mathrm{~nm}$, and they showed a $\lambda_{\max }$ of $440 \mathrm{~nm}$ in the UV-Vis spectrum, due to the presence of potentially reducing compounds such as polyphenols (flavonoids). The addition of surfactants to the medium, with the exception of Tween 80 (-19.9), improved the stabilization of the nanostructures with respect to the aqueous medium (-21.3), being SDS the best (-41.8). Leea coccinea leaf was confirmed as a valuable bioresource to the synthesis of antibacterial silver nanoparticles through a simple, fast and environmentally safe technology.

\section{Abbreviations}

AgNPs: Silver nanoparticles; FTIR: Fourier transform infrared spectroscopy; UV-VIS: Ultraviolet-visible; nm: Nanometer; NPs: Nanoparticles; MNPs: Metallic nanoparticles; W/V: Weight/volume; SEM: Scanning electron microscopy; EDX: Energy dispersive X-ray; DLS: Dynamic Light Scattering.

\section{Declarations}

\section{Conflict of Interest}

There are no conflicts of interest to be declared.

\section{Funding}

These results were supported by National Program of Nanoscience and Nanotechnology of Ministry of Science and Environmental from Cuba.

\section{Acknowledgments}

Authors wish to acknowledge the Advanced Studies Center of Cuba for providing research facilities to the characterization studies. Also, the National Program of Nanoscience of Nanotechnology from Cuba for providing financial support to make possible this research. Special thanks to Dr. Eduardo Sistach for reviewing the manuscript. Technical support of technicians Cecil González Suarez, Lazara Deisy Gonzalez Gutierrez and Eira Maria Serrano Herrera (from CENSA) and Dania Mora Vazquez, Ananayla Vizcaíno Acosta and Ahmed Valdes (from CEA) were indispensable to successful ending of the study.

\section{Availability of data and materials}

All data generated or analyzed during this study are included in this article. 


\section{Ethics approval and consent to participate}

All authors have read and agreed the ethics for publishing the manuscript.

\section{Consent for publication}

All authors approved the consent for publishing the manuscript to Journal of Bioresources and Bioprocessing.

\section{Authors $\rrbracket$ contributions}

Lianet Díaz performed the experiments of phytochemical screening, analyzed the data, contributed, prepared figures and/or tables, or reviewed drafts of the paper, and approved the final draft.

Annie Rubio designed and performed the experiments, statistical analysis, prepared figures and/or tables, authored or reviewed drafts of the paper, approved the final draft.

Beatriz Alvarez performed the experiments, prepared figures and/or tables, authored or reviewed drafts of the paper, approved the final draft.

Verónica Navarro performed the experiments of characterization of the suspension of nanoparticles, analyzed the UV-VIS spectra data, prepared photos, authored or reviewed drafts of the paper, approved the final draft.

Adrian González participated in the design of the kinetics study. Prepared kinetics graphics, statistical analysis, authored or reviewed drafts of the paper, approved the final draft.

Oriela Pino designed and supervised the experiments, analyzed the data, reviewed drafts of the paper, approved the final draft, significant opportunities and applications of nanotechnology in plant protection.

María del Carmen Travieso designed and performed the experiments, processing of primary data, interpretation and integration of results, and written the document.

\section{References}

1. Quiñones PD (2017) Resistencia antimicrobiana: evolución y perspectivas actuales ante el enfoque «Una salud». Rev Cubana Med Trop 69(3):1-17

2. WHO (2016) Global Action Plan On Antimicrobial Resistance. World Health Organization, Geneva. http://www.who.int/iris/handle/10665/193736

3. WHO (2017) Resistencia a los antimicrobianos. World Health Organization, Geneva. http://origin.who.int/mediacentre/factsheets/fs194/es/

4. UN (2017) Resistencia a los antimicrobianos: investigar la dimensión ambiental. United Nations. Programa de las Naciones Unidas para el Medio Ambiente. Informe del PNUMA Fronteras. https://wedocs.unep.org/bitstream/handle/20.500.11822/22263/Frontiers_2017_CH1_SP.pdf? sequence=6\&isAllowed=y 
5. OIE (2013) El concepto Una Sola Salud: enfoque de la OIE. Paris: Organización Mundial de Sanidad Animal.

http://www.oie.int/fileadmin/Home/esp/Publications_\%26_Documentation/docs/pdf/bulletin/Bull_20131-ESP.pdf

6. FAO (2016) El Plan de Acción de la FAO sobre RAM en la Alimentación y la Agricultura 2016-2020. Roma: Organización de las Naciones Unidas para la Alimentación y la Agricultura. http://www.fao.org/3/b-i6141s.pdf

7. Serra M (2017) La resistencia microbiana en el contexto actual y la importancia del conocimiento y aplicación en la política antimicrobiana. Revista Habanera de Ciencias Médicas 16(3):402-419

8. Travieso MC, Rubio OA, Pino PO (2017) Las nanopartículas a partir de plantas como base para el diseño de nuevos antimicrobianos. Revista Cubana de Farmacia 51(4):1-20

9. Singh C, Kumar J, Kumar P, Singh B, Tiwari KN, Mishra SK et al (2019) Green synthesis of silver nanoparticles using aqueous leaf extract of Premna integrifolia (L.) rich in polyphenols and evaluation of their antioxidant, antibacterial and cytotoxic activity. Biotechnology Biotechnological Equipment 33(1):359-371. https://www.doi.org/10.1080/13102818.2019.1577699

10. Mohammadlou M, Maghsoudi H, Jafarizadeh MH (2016) A review on green silver nanoparticles based on plants: Synthesis, potential applications and eco-friendly approach. International Food Research Journal 23(2):446-463

11. Roy A (2017) Synthesis of silver nanoparticles from medicinal plants and its biological application: A review. Research Reviews in Bioscieces 12(4):1-11

12. Sarkar D, Paul G (2017) Green synthesis of silver nanoparticles using Mentha asiatica (Mint) extract and evaluation of their antimicrobial potential. International Journal of Current Research in Biosciences Plant Biology 4(1):77-82. http://www.doi.org/10.20546/ijcrbp.2017.401.009

13. Rao NH, Lakshmidevi N, Pammi SV, Kollu P, Ganapaty S, Lakshmi P (2016) Green synthesis of silver nanoparticles using methanolic root extracts of Diospyros paniculata and their antimicrobial activities. Materials Science Engineering C 62:553-557. http://www.doi.org/10.1016/j.msec.2016.01.072

14. Kasithevar M, Saravanan M, Prakash P, Kumar H, Ovais M, Barabadi H et al (2017) Green synthesis of silver nanoparticles using Alysicarpus monilifer leaf extract and its antibacterial activity against MRSA and CoNS isolates in HIV patients. Journal of Interdisciplinary Nanomedicine 2(2):131-141. http://www.doi.org/10.1002/jin2.26

15. Travieso MC, Rubio A, Corzo M, Pino O (2018) Silver nanoparticles obtained from the residual extract of the hydro distillation of Thymus vulgaris L. and its effect on Xanthomonas phaseoli pv. phaseoli. Revista de Protección Vegetal 33(3). http://opn.to/a/j0pZI

16. Rautela A, Rani J, Debnath M (2019) Green synthesis of silver nanoparticles from Tectona grandis seeds extract: characterization and mechanism of antimicrobial action on different microorganisms. Journal of Analytical Science Technology 10(5). https://www.doi.org/10.1186/s40543-018-0163-z

17. Huang W, Yan M, Duan H, Bi Y, Cheng X, Yu H (2020) Synergistic Antifungal Activity of Green Synthesized Silver Nanoparticles and Epoxiconazole against Setosphaeria turcica. Journal of Nanomaterials ID 9535432 https://www.doi.org/10.1155/2020/9535432 
18. Haggag GE, Elshamy AM, Rabeh MA, Salem M, Samir A, Muhsinah AB et al (2019) Antiviral potential of green synthesized silver nanoparticles of Lampranthus coccineus and Malephora lutea. Int J Nanomed 14:6217-6229

19. Gupta D, Chauhan P (2017) Green Synthesis of Silver Nanoparticles Involving Extract of Plants of Different Taxonomic Groups. Journal of Nanomedicine Research 5(2): 00110. https://www.doi.org/ 10.15406/jnmr.2017.05.00110

20. Meena PR, Singh AP, Tejavath KK (2020) Biosynthesis of Silver Nanoparticles Using Cucumis prophetarum Aqueous Leaf Extract and Their Antibacterial and Antiproliferative Activity Against Cancer Cell Lines. ACS Omega 5:5520-5528. http://pubs.acs.org/journal/acsodf [consultado 17 de mayo del 2020]

21. Kumar H, Bhardwaj K, Kuča K, Kalia A, Nepovimova E, Verma R et al (2020) Flower-Based Green Synthesis of Metallic Nanoparticles: Applications beyond Fragrance. Nanomaterials 10(766). https://www.doi.org/10.3390/nano10040766

22. Mosaviniya M, Kikhavani T, Tanzifi M, Tavakkoli M, Tajbakhsh P, Lajevardi A (2019) Facile green synthesis of silver nanoparticles using Crocus Haussknechtii Bois bulb extract: Catalytic activity and antibacterial properties. Colloid Interface Science Communications 33:1-11. https://www.doi.org/ 10.1016/j.colcom.2019.100211

23. Behravan M, Panahi AH, Naghizadeh A, Ziaee M, Mahdavi R, Mirzapour A (2018) Facile green synthesis of silver nanoparticles using Berberis vulgaris leaf and root aqueous extract and its antibacterial activity. Int J Biol Macromol. https://doi.org/10.1016/j.ijbiomac.2018.11.101

24. Singh D, Siew Y, Chong T, Yew H, Ho SS (2019) Identification of Phytoconstituents in Leea indica (Burm. F.) Merr. Leaves by High Performance Liquid Chromatography Micro Time-of-Flight Mass Spectrometry. Molecules 24(714):1-11. http://www.doi.org/10.3390/molecules24040714

25. Travieso MC, Rubio OA, Alvarez PB, Corzo LM, Díaz PL, Acosta ME, Pino PO (2021) Biosynthesis of fluorescent silver nanoparticles from Leea coccinea leaves and their bacterial potentialities against Xanthomonas phaseoli pv phaseoli Bioresour. Bioprocess 8:3. doi: 10.1186/s40643-020-00534-2

26. Di Rienzo JA, Casanoves F, Balzarini MG, Gonzalez L, Tablada M, Robledo CW. InfoStat versión 2016. Grupo InfoStat, FCA, Universidad Nacional de Córdoba, Argentina. URL http://www.infostat.com.ar

27. Pino O, Sánchez Y, Rojas MM (2013) Plant secondary metabolites as an alternative in pest management. I : Background, research approaches and trends. Revista de Protección Vegetal 28(2):81-94

28. Singh A, Gaud B, Jaybhaye S (2020) Optimization of synthesis parameters of silver nanoparticles and its antimicrobial activity. Materials Science for Energy Technologies 3:232-236.

https://www.doi.org/10.1016/j.mset.2019.08.004

29. Oluwasogo A, Amoo AF, Fehintoluwa E, Adelani AAT, Oluwasesan M, Rita C et al (2019) Silver nanoparticle synthesis by Acalypha wilkesiana extract: phytochemical screening, characterization, influence of operational parameters, and preliminary antibacterial testing. Heliyon 5:1-8. https://www.doi.org/10.1016/j.heliyon.2019.e02517

30. Nasar MQ, Zohra T, Khalil AT, Saqib S, Ayaz M, Ahmad A et al (2019) Seripheidium quettense mediated green synthesis of biogenic silver nanoparticles and their theranostic applications. Green Chem Lett Rev 12(3):310-322. https://www.doi.org/10.1080/17518253.2019.1643929 
31. Handayani W, Ningrum AS, Imawan C (2020) The Role of pH in Synthesis Silver Nanoparticles Using Pometia pinnata (Matoa) Leaves Extract as Bioreductor. Journal of Physics: Conference Series https://www.doi.org/10.1088/1742-6596/1428/1/012021

32. Chen J, Li S, Luo J, Wang R, Ding W (2016) Enhancement of the Antibacterial Activity of Silver Nanoparticles against Phytopathogenic Bacterium Ralstonia solanacearum by Stabilization. Journal of Nanomaterials. https://www.doi.org/10.1155/2016/7135852

33. 33. Moodley JS, Babu S, Krishna N, Pillay K, Govender P (2018) Green synthesis of silver nanoparticles from Moringa oleifera leaf extracts and its antimicrobial potential. Adv Nat Sci NanoSci NanoTechnol 9:1-9. https://www.doi.org/10.1088/2043-6254/aaabb2

34. Bélteky P, Rónavári A, Igaz N, Szerencsés B, Tóth IY, Pfeiffer I, Kiricsi M, Kónya Z (2019) Silver nanoparticles: aggregation behavior in biorelevant conditions and its impact on biological activity. Int $J$ Nanomedicine 14:667-687. https://doi.org/10.2147/IJN.S185965

35. Duval RE, Gouyau J, Lamouroux E (2019) Limitations of Recent Studies Dealing with the Antibacterial Properties of Silver Nanoparticles: Fact and Opinion. Nanomaterials 9(1775):1-22. https://www.doi.org/10.3390/nano9121775

36. Salvioni L, Galbiati E, Collico V, Alessio G, Avvakumova S, Corsi F, Tortora P, Prosperi D, Colombo M (2017) Negatively charged silver nanoparticles with potent antibacterial activity and reduced toxicity for pharmaceutical preparations. Int J Nanomedicine 12:2517-2530. https://doi.org/10.2147/IJN.S127799

37. Roy S, Anantharaman P (2017) Biosynthesis of Silver Nanoparticles by Chaetomorpha antennina (Bory de Saint-Vincent) Kutzing with Its Antibacterial Activity and Ecological Implication. Journal of Nanomedicine Notechnology 8(5):1-9. Doi:10.4172/2157-7439.1000467

38. Mohanta YK, Panda SK, Bastia AK, Mohanta TK (2017) Biosynthesis of Silver Nanoparticles from Protium serratum and Investigation of their Potential Impacts on Food Safety and Control. Front Microbiol 8(626). https://www.doi.org/ 10.3389/fmicb.2017.00626

39. Bae E, Park H, Park J, Yoon J, Kim Y, Choi K et al (2011) Effect of Chemical Stabilizers in Silver Nanoparticle Suspensions on Nanotoxicity. Bulletin Korean Chemical 32(2):613-619. https://www.doi.org/10.5012/bkcs.2011.32.2.613

\section{Figures}



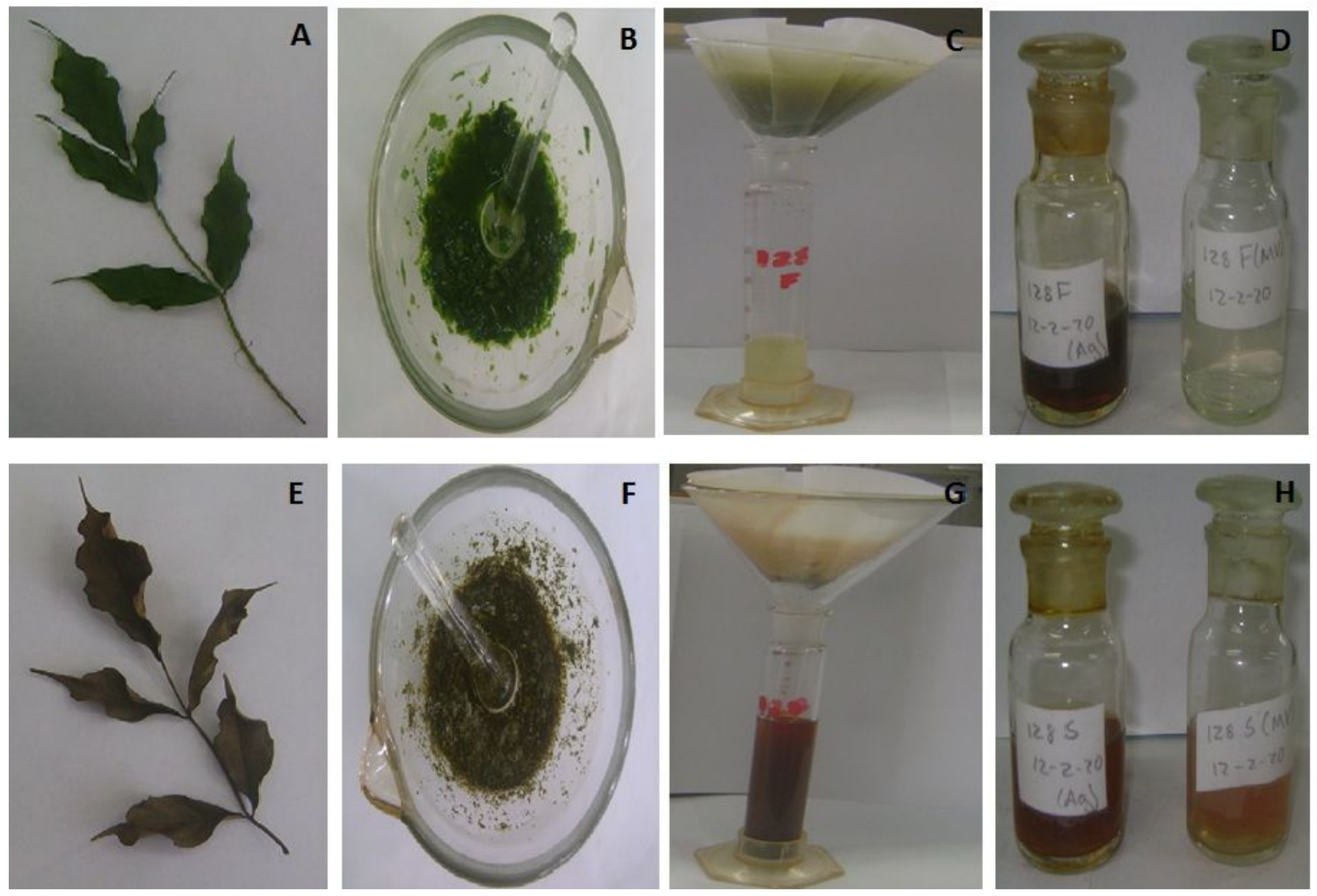

Figure 1

Scheme of the biosynthesis of AgNPs synthesized from L. coccinea. From plant material fresh (A-D) and dry (E-H). A and E: Plant Material; B and F: Maceration; $C$ and G: Filtration; D and H: Colloidal suspension of AgNPs

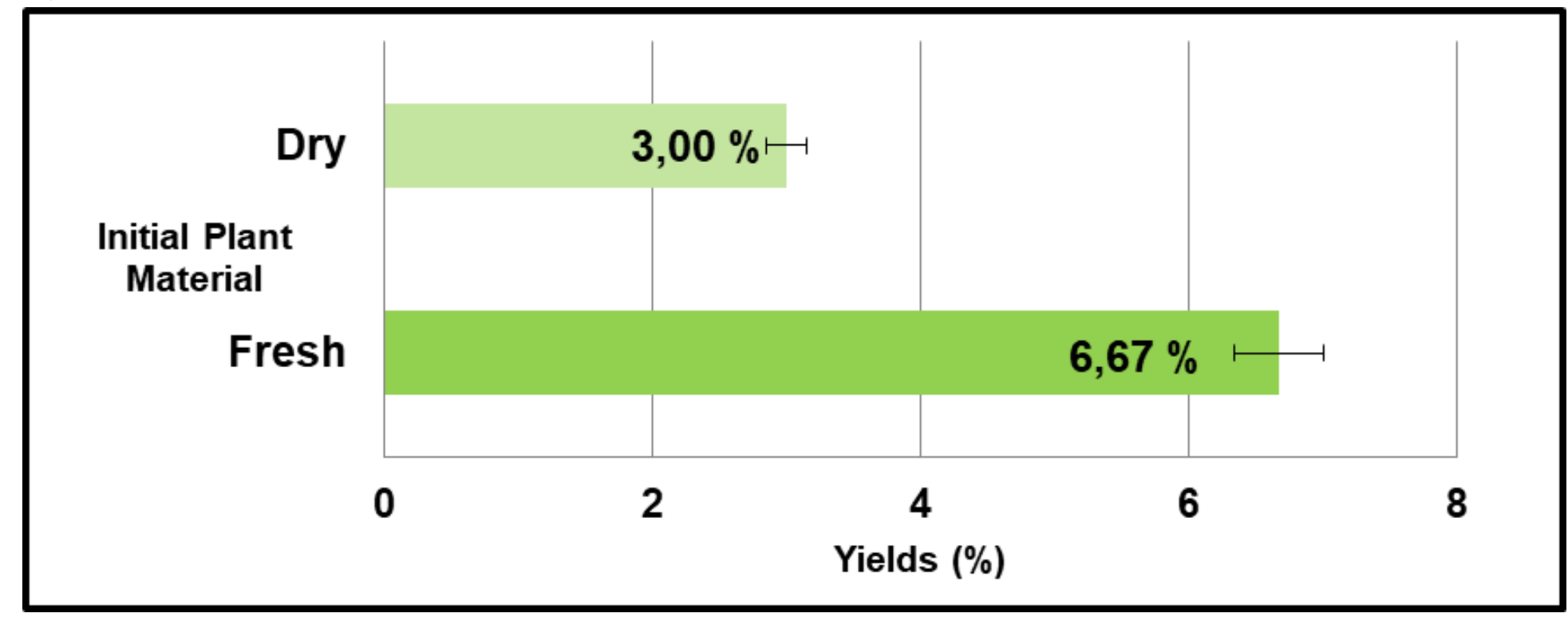


Figure 2

Yields of the synthesis of AgNPs with plant material of L. coccinea (fresh and dry)

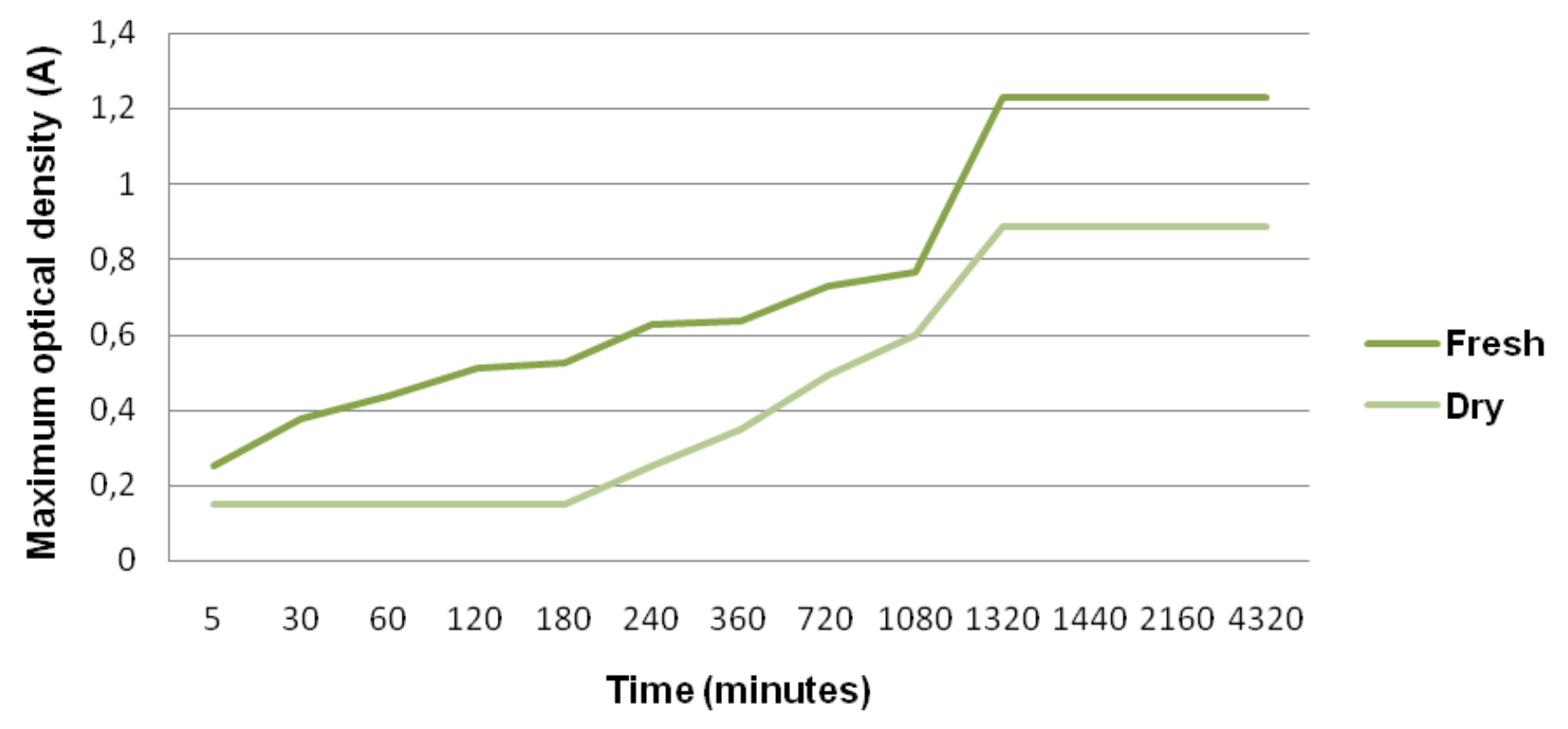

Figure 3

Curves of the kinetic studies of the bio-reduction reaction with fresh and dry plant material

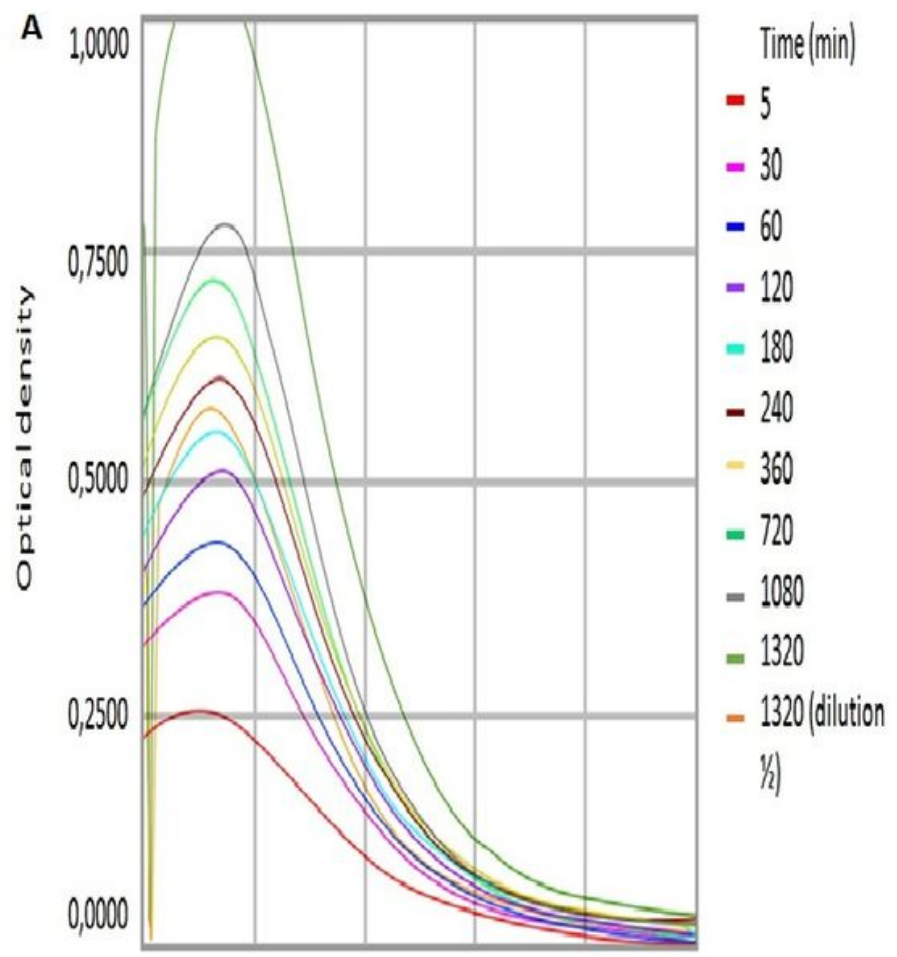

$380,0 \quad 464,0 \quad 548,0 \quad 632,0 \quad 716,0 \quad 800,0$

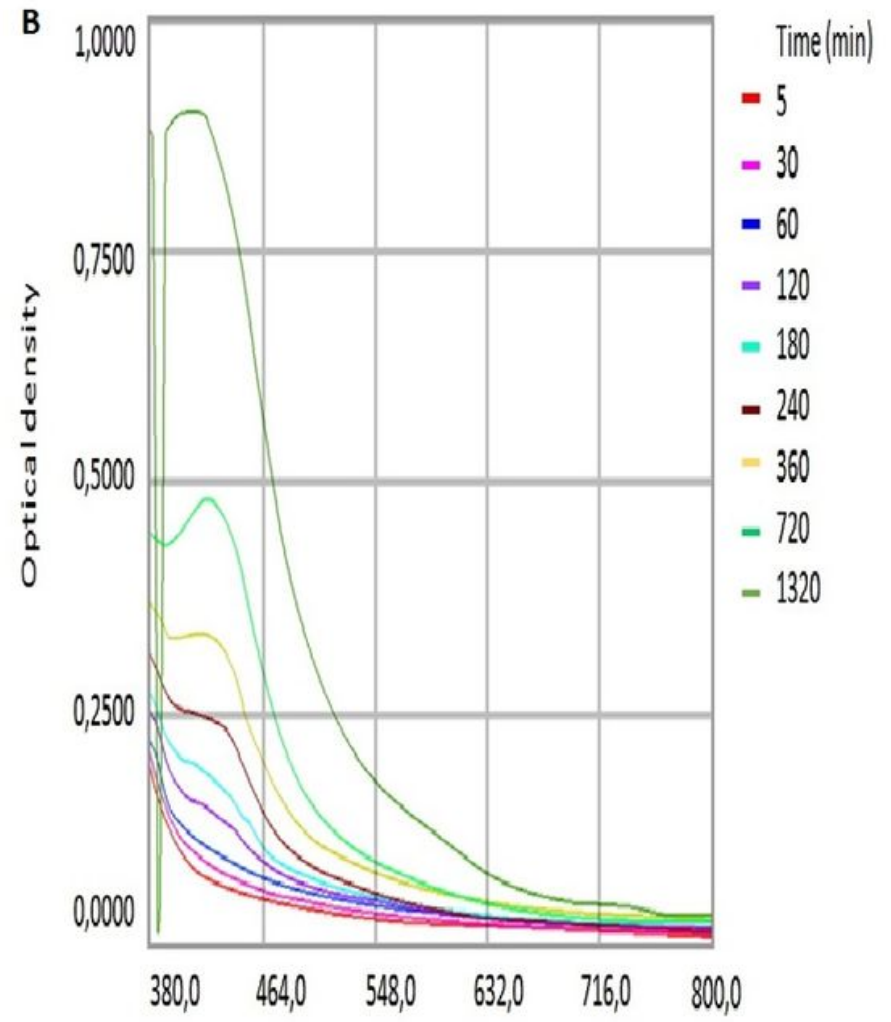

$\lambda(\mathrm{mm})$ 
Figure 4

Bio-reduction reaction during 24 hours of the synthesis of AgNPs with L. coccinea. A: UV-Vis absorption spectra at different times (fresh plant material); B: UV-Vis absorption spectra at different times (dry plant material)

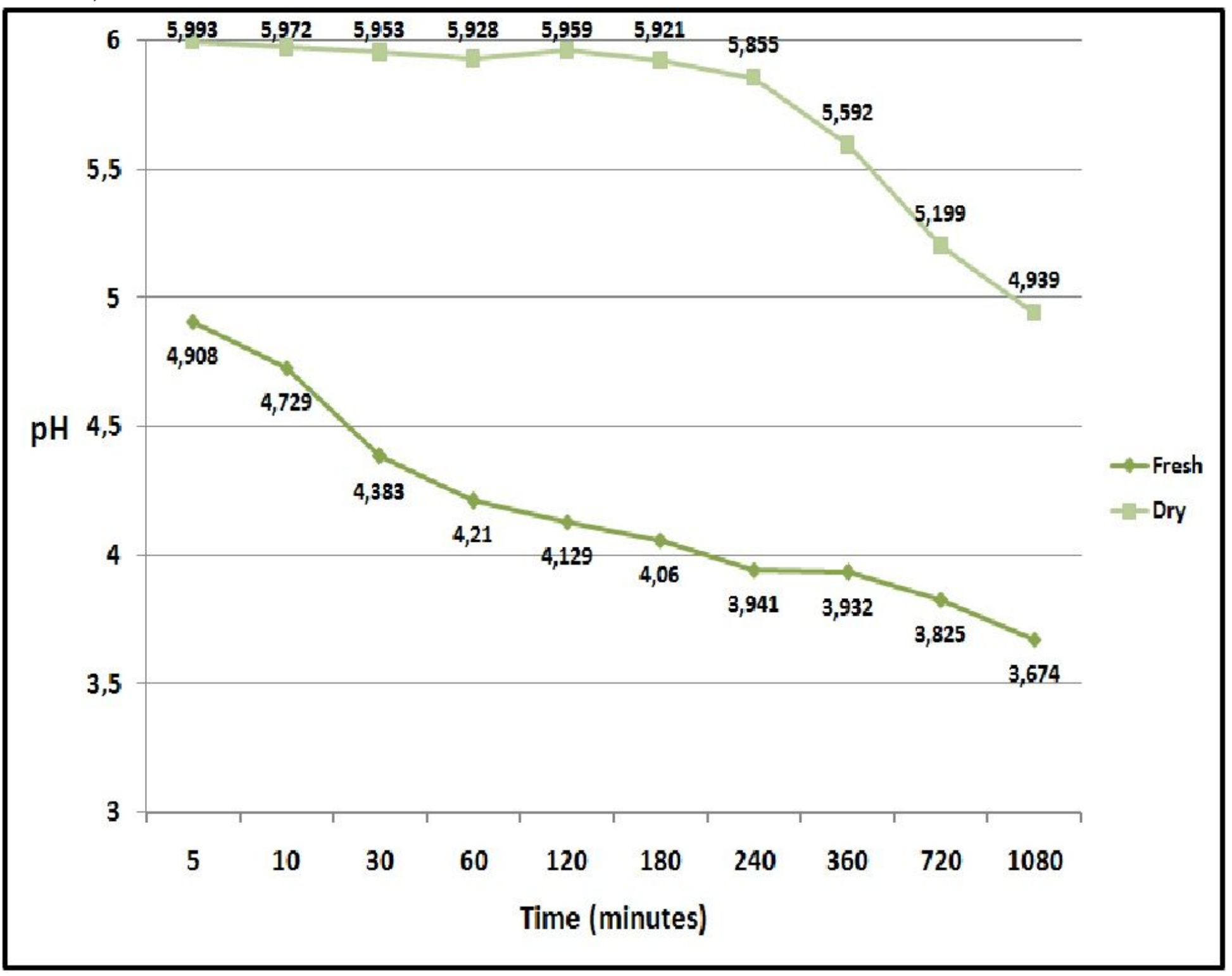

Figure 5

Variation of $\mathrm{pH}$ during the bio-reduction reaction with L. coccinea (fresh and dry plant material) 

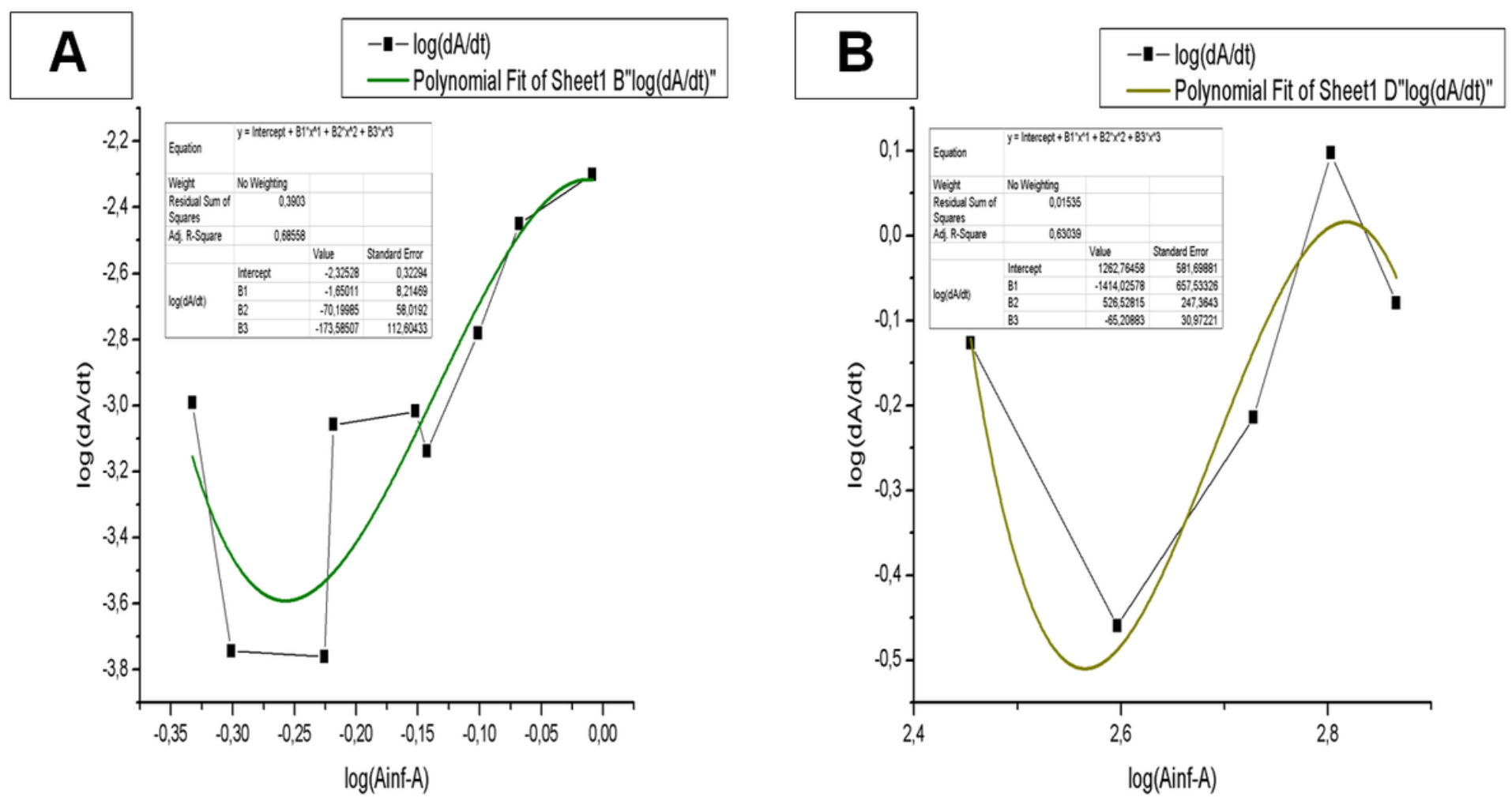

\section{Figure 6}

Curve of the study of kinetics of the bio-reduction reaction from L. coccinea by the differential method. A: Fresh plant material; B: Dry plant material
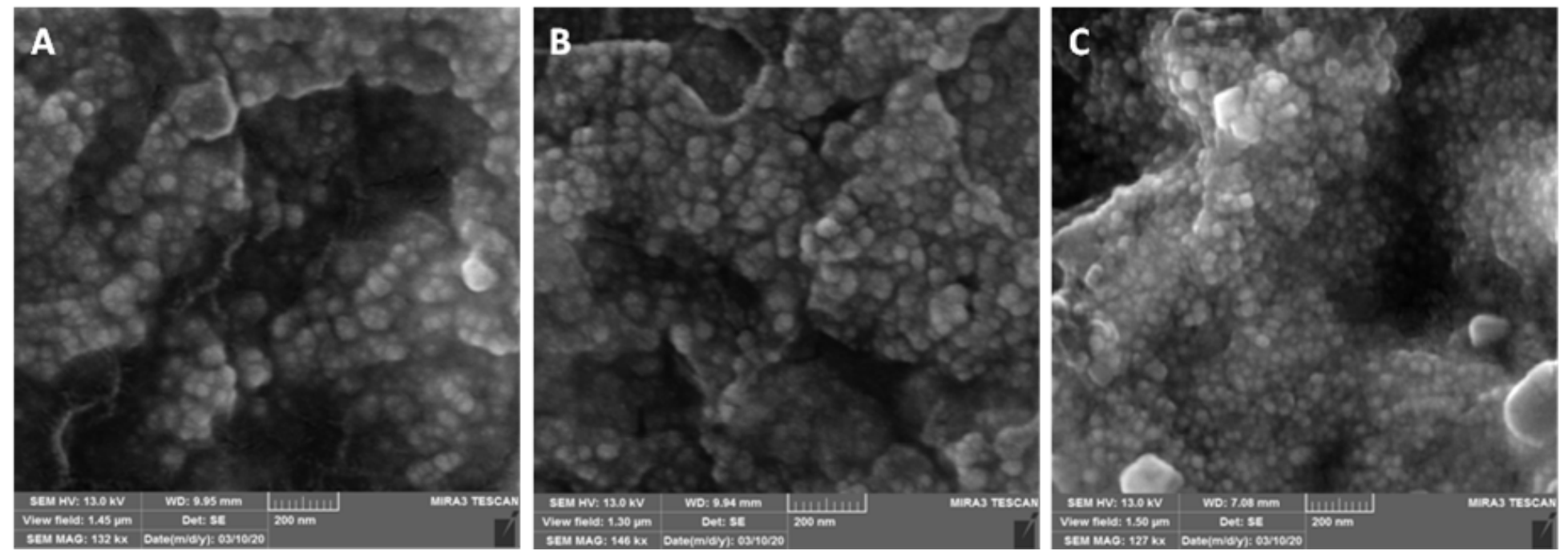

\section{Figure 7}

SEM images of AgNPs synthesized with fresh leaves of L. coccinea at different times of bio-reduction. A: 6 hours; B: 12 hours; and C: 24 hours 


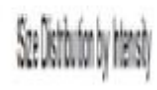

A

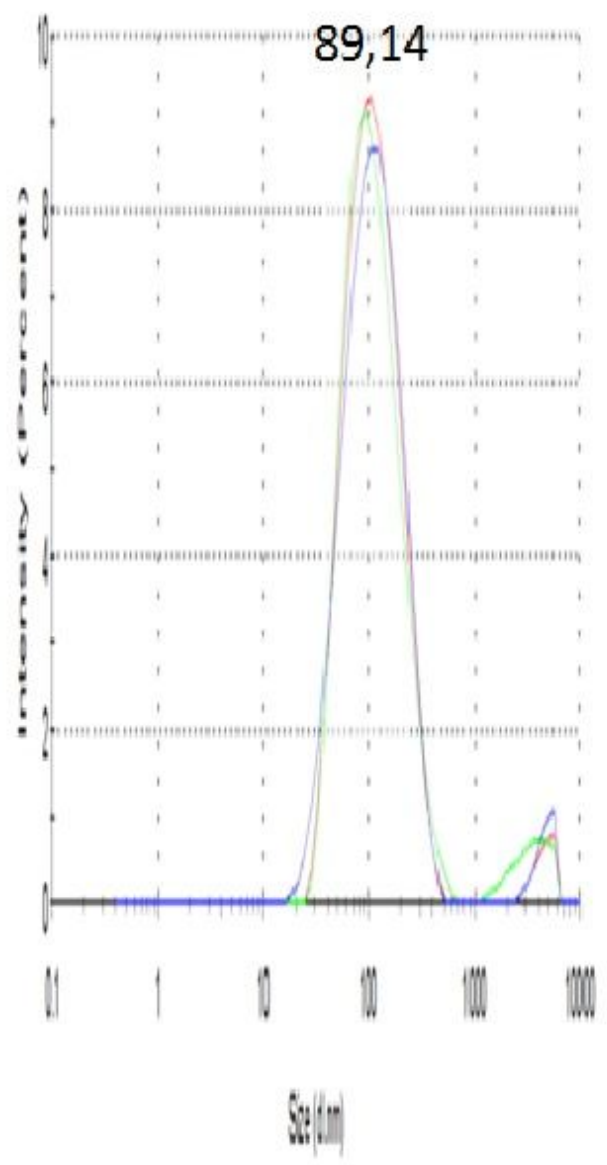

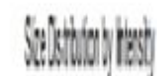

B

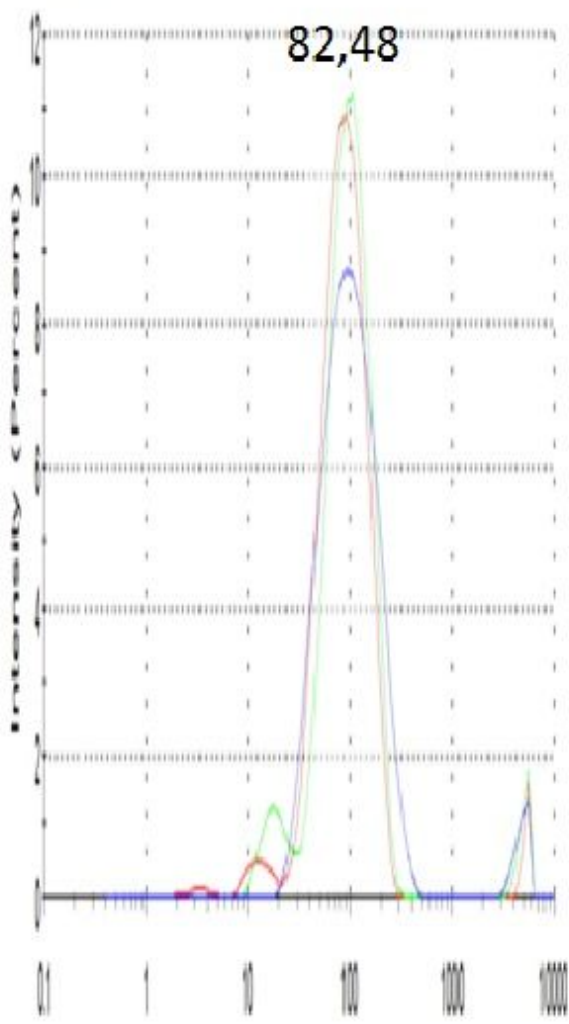

bivin
Gentoung

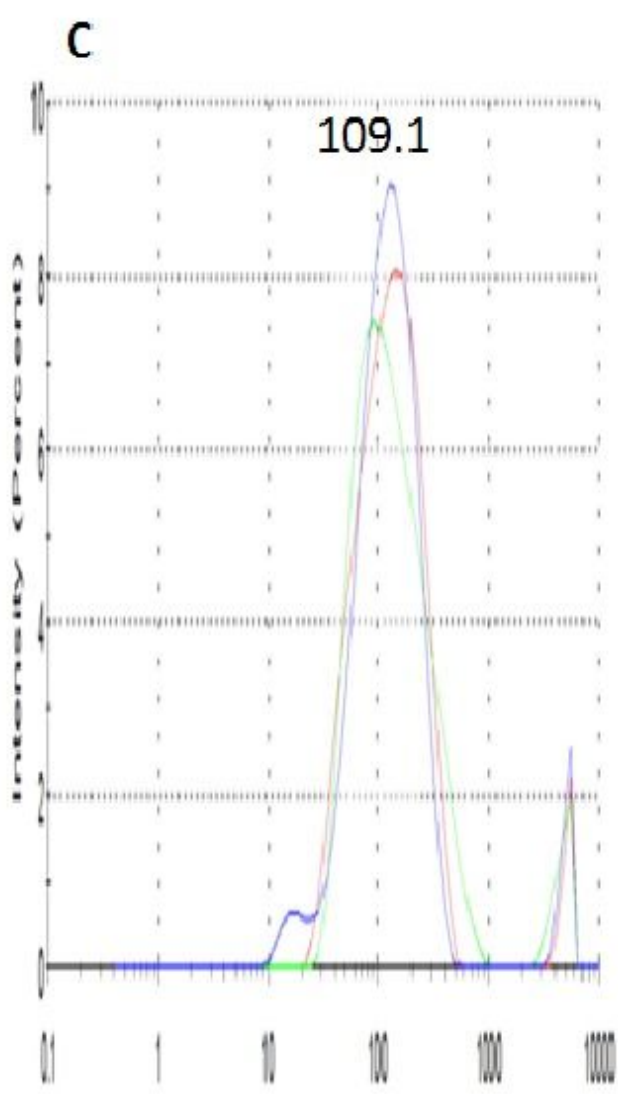

(4) 10

\section{Figure 8}

Particle size of AgNPs synthesized with fresh leaves of L. coccinea. A: 6 hours, B: 12 hours and C: 24 hours 


\section{$\mathrm{Ag}(\%)$}
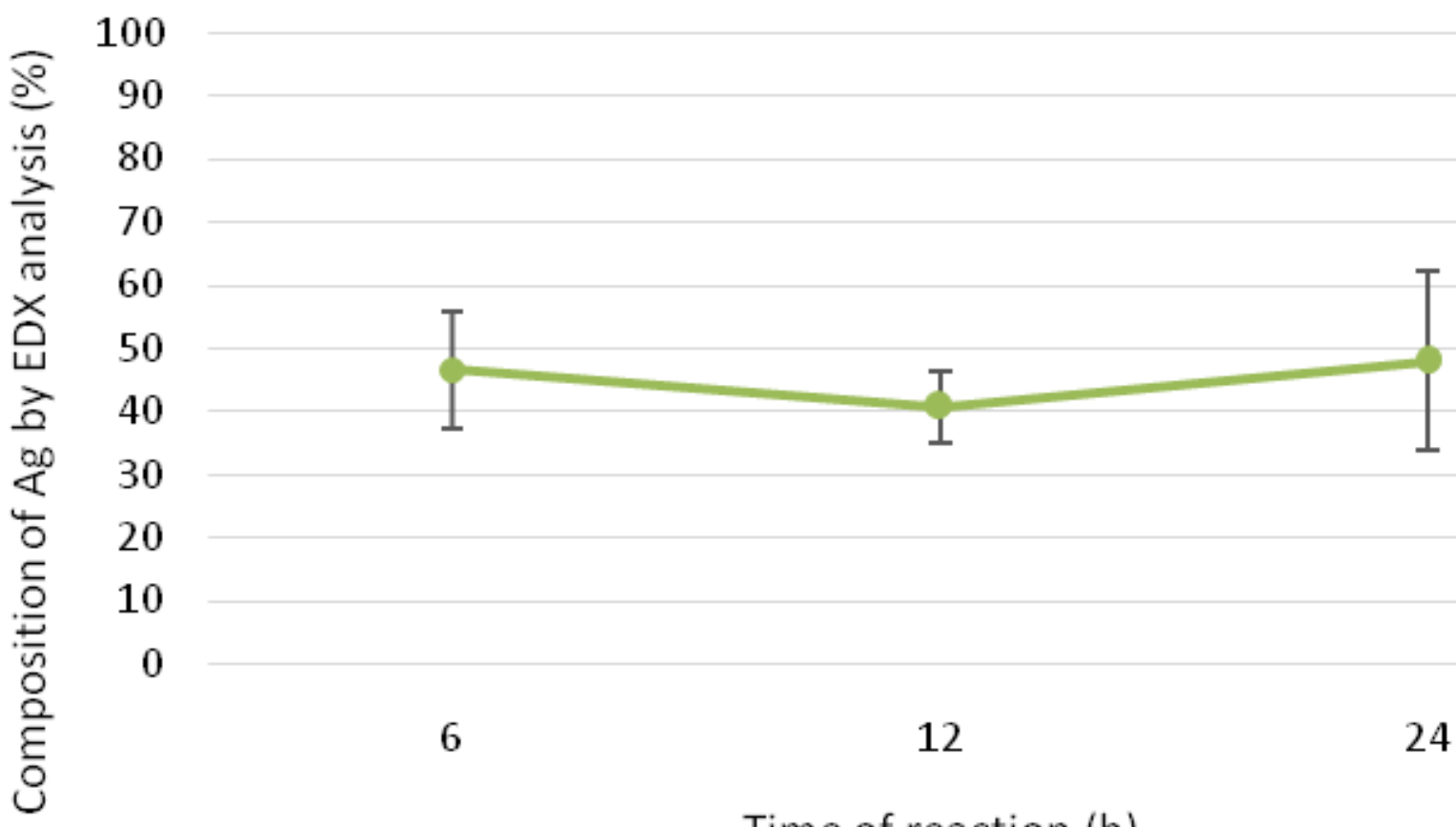

6

12

Time of reaction $(\mathrm{h})$

Figure 9

EDX profile of the composition (Ag) of the AgNPs synthesized with fresh leaves of L. coccinea at different times

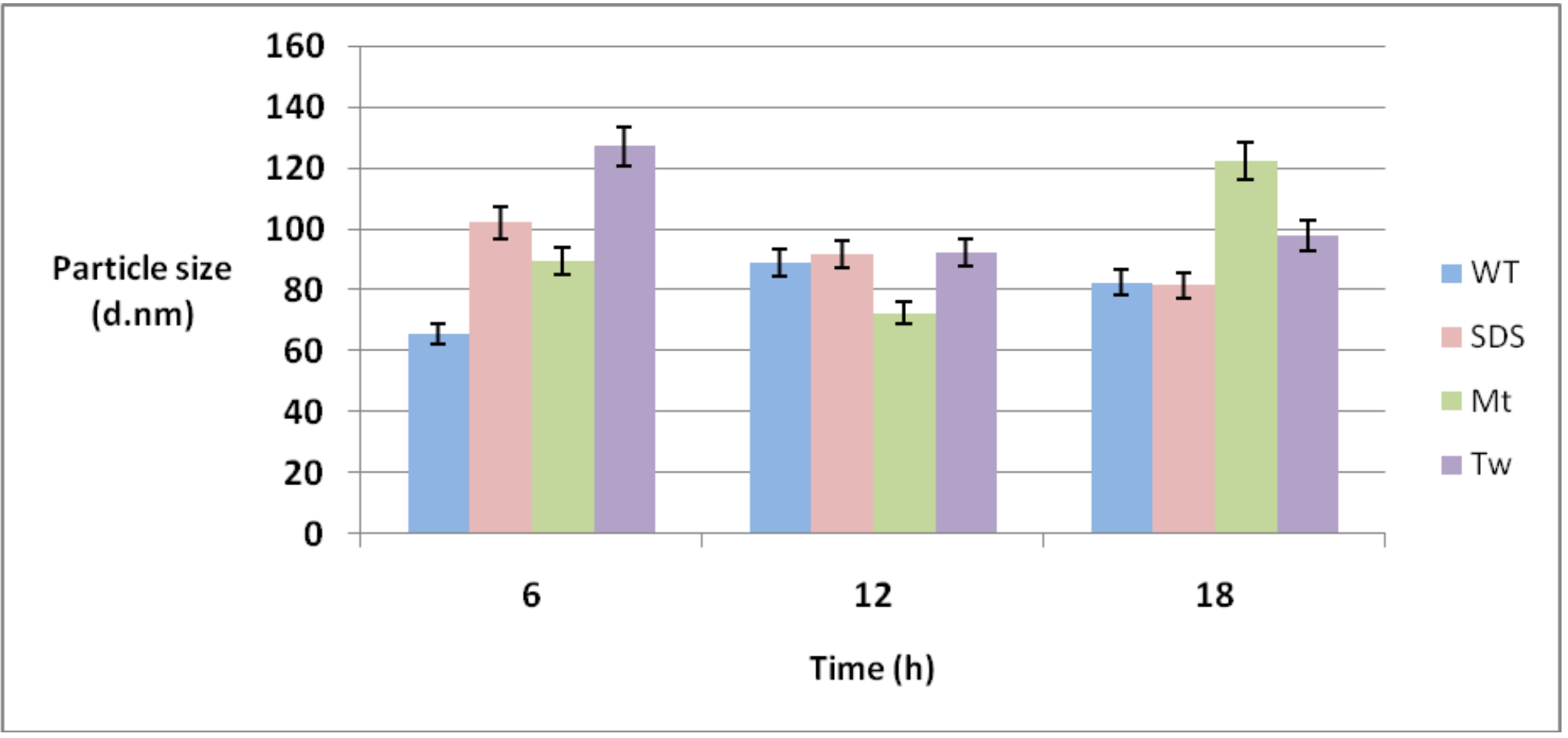

Figure 10 
Influence of surfactants on particle size of the AgNPs synthesized with fresh leaves of L. coccinea
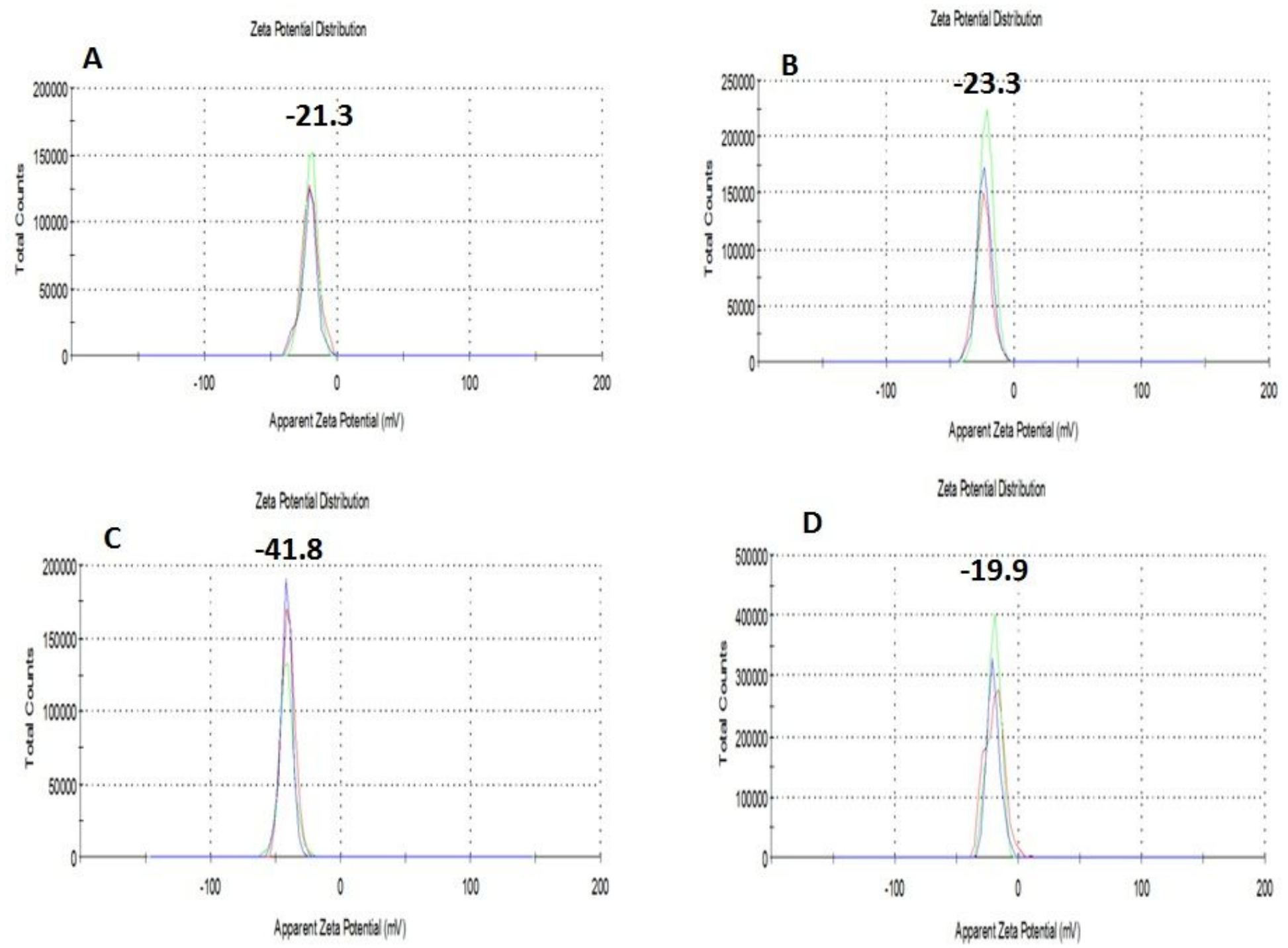

\section{Figure 11}

Influence of surfactants on the Z Potential. A: Water, B: Maltose (0.5\%), C: SDS (0.5\%), and D: Tw 80 (0.5\%)

\section{Supplementary Files}

This is a list of supplementary files associated with this preprint. Click to download.

- Graphicalabstract.docx 